\title{
Ventilator-Associated Lung Disease in an Emergency Intensive Care Unit: Epidemiological, Clinical and Bacteriological Characteristics and Antibiotic Resistance Status: Study of 202 Cases
}

\author{
I. Karrati ${ }^{1 *}$, L. Ait Said ${ }^{1}$, M. Diakité ${ }^{1}$, A. Hilmi ${ }^{1}$, M. Khallouki ${ }^{2}$, K. Zahlane ${ }^{1}$
}

\author{
${ }^{1}$ Microbiology Laboratory, Ibn Tofail Hospital, CHU Mohamed 6 Marrakech, FMPM, Rue Abdelouahab Derraq, Marrakech 40000, \\ Morocco \\ ${ }^{2}$ Resuscitation Service, Ibn Tofail Hospital, CHU Mohamed 6 Marrakech, FMPM, Rue Abdelouahab Derraq, Marrakech 40000,
} Morocco

\begin{abstract}
Nosocomial pneumonia is the second most common cause of nosocomial infection in the intensive care unit. They pose serious diagnostic, therapeutic and economic problems and increase the risk of death by increasing the length of stay in the ICU. Our work is a retrospective descriptive study of all patients hospitalized in the ICU who presented with ventilator-associated pneumonia (VAP) over a period of one year in the intensive care unit of Ibn Tofail Hospital in Marrakech. In our study, gram-negative bacilli were the most frequently isolated germs, with Acinetobacter baumannii predominating. Gram-positive cocci came in second place, represented by Staphylococcus aureus. In $69 \%$ of cases, the infection was polymicrobial. The resistance rate of the isolated strains was high; $95.7 \%$ of Acinetobacter baumannii were resistant to imipenem. Isolated strains of Enterobacteriaceae were resistant to the combination of amoxicillin and clavulanic acid in $53.3 \%$ of cases, to $\mathrm{C} 3 \mathrm{G}$ in $30.7 \%$ of cases, to imipenem in $2.7 \%$ of cases, to amikacin in $1.4 \%$ of cases and to cotrimoxazole in $41.7 \%$ of cases. Staphylococcus aureus resistance was $4 \%$ to penicillin $\mathrm{M}$ and decreased compared to other antibiotics. The emergence of resistance to antibiotics of last resort in therapy defines multi-resistant bacteria. These were isolated in 38\% of cases. Acinetobacter baumannii was the most isolated multidrug-resistant pathogen. In the light of this study, it appears that good management of antibiotic prescriptions, strict application of hygiene and asepsis measures as well as resistance monitoring within each ICU are necessary for the reduction of nosocomial pneumopathies with multi-resistant germs.

Keywords: Ventilator-associated pneumonia- Epidemiology- Antibiotic resistance - Intensive care unit (ICU).

Copyright $\odot 2022$ The Author(s): This is an open-access article distributed under the terms of the Creative Commons Attribution 4.0 International License (CC BY-NC 4.0) which permits unrestricted use, distribution, and reproduction in any medium for non-commercial use provided the original author and source are credited.
\end{abstract}

\section{INTRODUCTION}

Nosocomial infections are recognised as major public health problems in almost all countries, due to their frequency, severity and the cost of hospital care for patients. Ventilator-associated lung disease (VALD) is classically defined as occurring more than 48-72 hours after invasive mechanical ventilation via endotracheal intubation. The diagnosis is based on clinical, biological, radiological and bacteriological criteria.

The microorganisms involved are most often environmental bacteria that have acquired multiple resistances in the hospital environment, making their treatment difficult, despite the discovery of new antiinfective molecules. Therefore, we conducted a descriptive study on bronchial samples of patients hospitalized in the ICU of Ibn Tofail Hospital with the aim of establishing the epidemiological and bacteriological profile of nosocomial pneumopathies encountered, while determining the antibiotic resistance of the most frequently isolated germs.

\section{Material and Methods}

This is a retrospective study conducted at the microbiology laboratory in collaboration with the ICU department of Ibn Tofail Hospital in Marrakech over a period of one year from 1 January to 31 December 2019.

Bacteriological samples are taken in case of infection established on a set of clinical, biological and radiological arguments. They are accompanied by the necessary clinical information. The different samples 
I. Karrati et al; Sch J App Med Sci, Jan, 2022; 10(1): 63-71

received in the laboratory are: Endo-tracheal aspiration (ETA), protected distal sampling (PDS), bronchoalveolar lavage (BAL). Each sample is examined macroscopically, microscopically in the fresh state and after gram staining, cultured, identified and finally tested for antibiotic sensitivity.

\section{RESULTS}

\section{1- Epidemiological data}

The average age of our patients was 35 years, with extremes ranging from 16 to 79 years. Traumatic pathology (severe head trauma and polytrauma) was the most common reason for hospitalization in the ICU. The duration of hospitalisation varied between 4 and 52 days with an average duration of 19 days. The average onset of nosocomial pneumonia was 6 days with a minimum of 2 days and a maximum of 25 days. In our study, 26 patients developed nosocomial pneumonia (NP) before 5 days, i.e. a rate of $43 \%$ of early NP, against 35 cases of late NP, i.e. a rate of $57 \%$. The presence of an associated infection was $15 \%$. Urinary tract infection was the most common.

All our patients benefited from resuscitation care consisting of: semi-seated position, intubation, ventilation, sedation, urinary and nasogastric probes.
The presence of a central venous catheterisation was found in $74 \%$. The presence of other invasive procedures (tracheotomy, reintubation, thoracic drainage, etc.) was found in $22 \%$.

Clinically and paraclinically, fever was found in $73.77 \%$ of cases, hypothermia in $5 \%$ of cases, and abundant purulent secretions were noted in $42.62 \%$ of cases. Hyperleukocytosis was present in $90.16 \%$. CRP was positive in $95.7 \%$ of cases with a value $>100 \mathrm{mg} / \mathrm{l}$ in $89.2 \%$ of cases. A radiological image suggestive of nosocomial pneumonia was found in $75.4 \%$ of cases. The evolution was unfavourable in almost $2 / 3$ of the cases.

\section{2- Microbiological data}

Of the 202 samples received, 115 were obtained by PDS, 37 by BAL and 50 by TEA. On direct examination, 154 samples were positive and 48 were negative. Gram staining showed the presence of BGN in 178 samples, CGP was present in 73 samples and BGP in 2 samples. For yeasts, we isolated them in 4 samples. Of the 154 direct examination positive samples, 137 were culture positive while 18 were sterile (Figure 1).

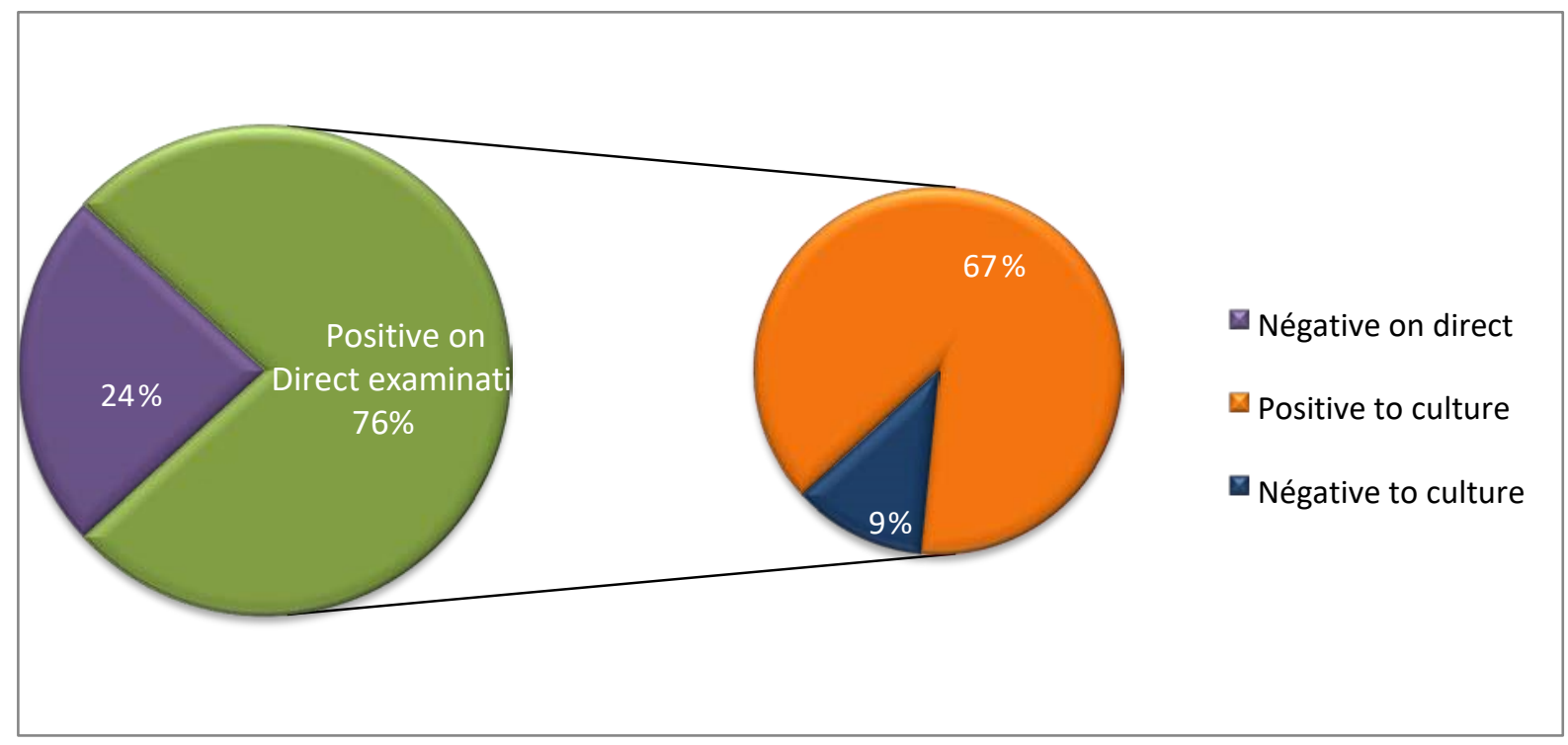

Figure 1: Frequency of positive samples

Of the positive cultures, 43 were single microbial. The number of germs isolated was 233, distributed over 14 different species. $72 \%$ of the germs were BGN, dominated mainly by Acinetobacter baumannii (30\%) (Table I).

Table I: Distribution of bacteria

\begin{tabular}{|l|l|l|}
\hline Bacteria & Number & Percentage \\
\hline Gram-negative bacilli (BGN) & 168 & $72 \%$ \\
\hline Entérobactéries & 76 & $32,5 \%$ \\
\hline Klebsiella pneumoniae & 27 & $11,6 \%$ \\
Proteus spp & 22 & $9,5 \%$ \\
E.coli & 7 & $3 \%$ \\
Enterobacter spp & 4 & $1,7 \%$ \\
\hline
\end{tabular}


I. Karrati et al; Sch J App Med Sci, Jan, 2022; 10(1): 63-71

\begin{tabular}{|l|l|l|}
\hline Bacteria & Number & Percentage \\
\hline Citrobacter spp & 2 & $0,8 \%$ \\
Serratia marcescens & 1 & $0,4 \%$ \\
Entérobactérie.spp & 13 & $5,5 \%$ \\
\hline BGN non fermentaires & 89 & $38,2 \%$ \\
\hline Acinetobacter baumannii & 70 & $30 \%$ \\
Pseudomonas aeruginosa & 19 & $8,2 \%$ \\
\hline BGN exigeants : Haemophilus influenzae & 3 & $1,3 \%$ \\
\hline Gram- positive cocci (CGP) & 65 & $28 \%$ \\
\hline Staphylocoque & 57 & $24,5 \%$ \\
\hline Staphylococcus aureus & 49 & $21 \%$ \\
\hline Staphylococcus à coagulase négative & 8 & $3,5 \%$ \\
\hline Streptocoque : Streptococcus pneumoniae & 7 & $3 \%$ \\
\hline Entérocoque & 1 & $0,4 \%$ \\
\hline
\end{tabular}

3- Antibiotic resistance profile of the main germs isolated

\section{Acinetobacter Baumannii}

Of the 70 strains of Acinetobacter baumannii isolated, the majority showed increased resistance to beta-lactams, aminoglycosides, ciprofloxacin and cotrimoxazole.
The rate of Acinetobacter baumannii resistant to imipenem (ABRI) and ceftazidime was $98.6 \%$ and $95.7 \%$ respectively.

All Acinetobacter baumannii isolates retained sensitivity to colistin (Figure 2).

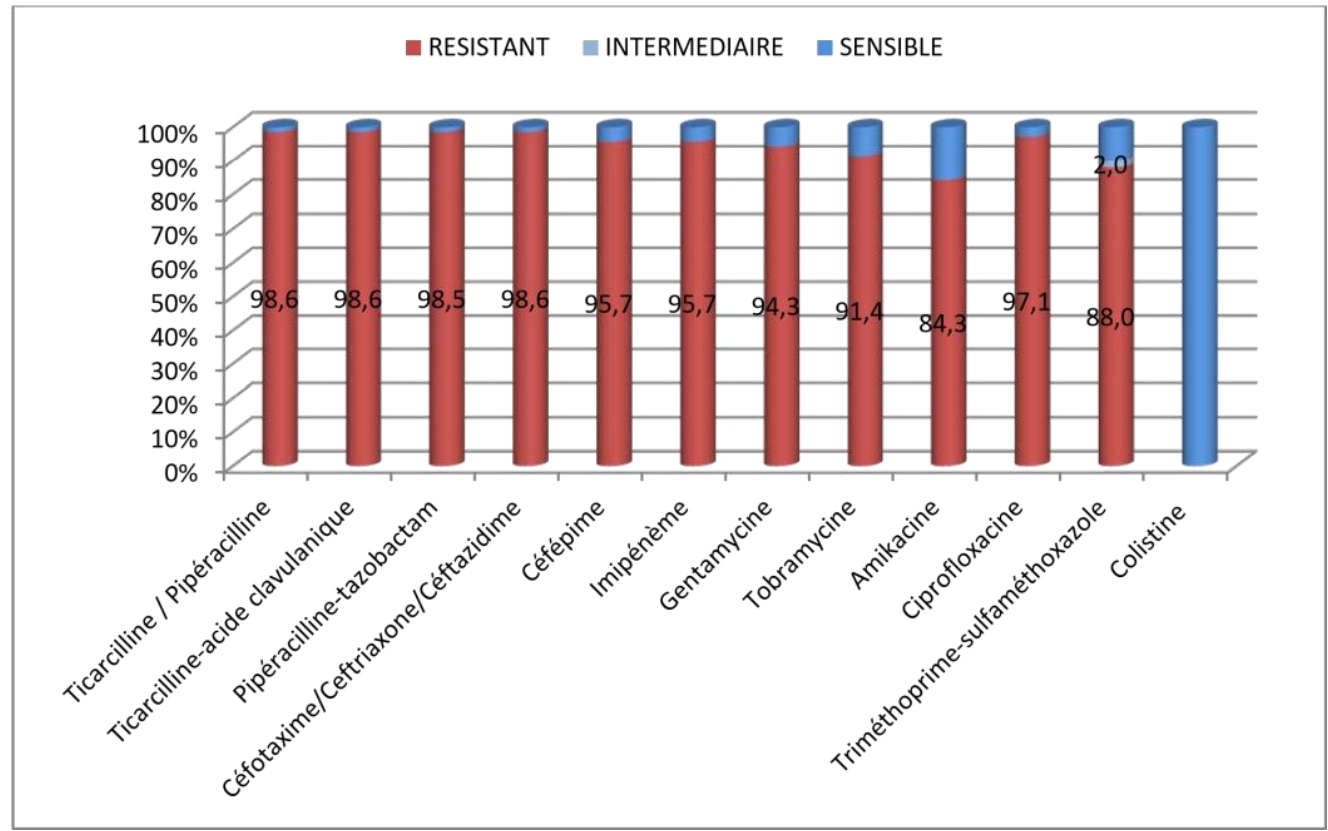

Figure 2: Resistance rates of Acinetobacter baumannii to different antibiotics (\%)

\section{Pseudomonas Aeruginosa}

The rate of Pseudomonas aeruginosa resistant to imipenem (IRAP), aztreonam and ticarcillin was $5.3 \% 14.3 \%$ and $26.3 \%$ respectively. All Pseudomonas aeruginosa isolates retained susceptibility to piperacillin-tazobactam and to ceftazidime and cefepime (Figure 3). 


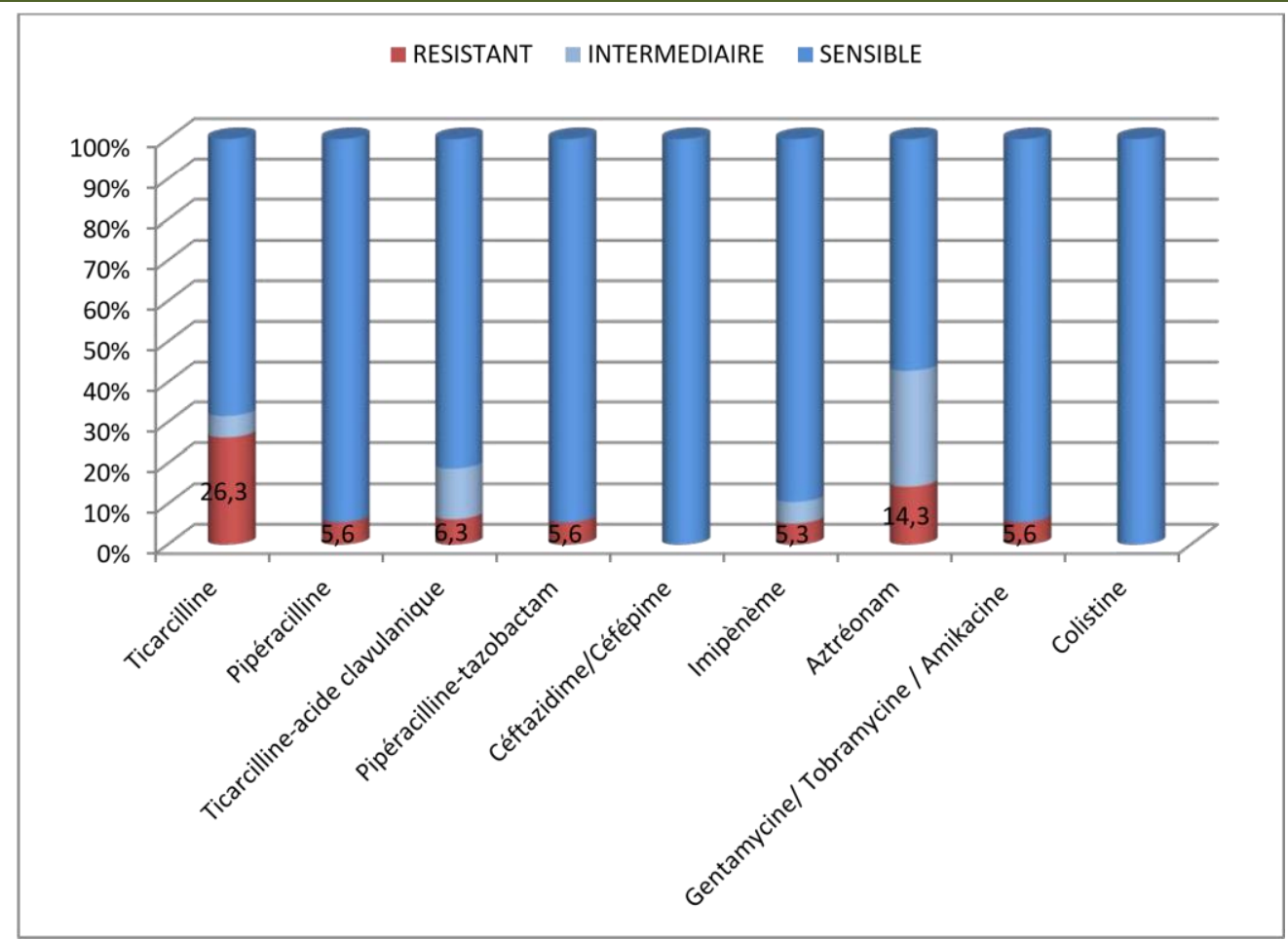

Figure 3: Resistance rates of Pseudomonas aeruginosa to different antibiotics (\%)

\section{Enterobacteriaceae}

The study of resistance to beta-lactam antibiotics revealed a high rate of resistance to amoxicillin, ticarcillin and piperacillin, a moderately high rate of resistance to amoxicillin and clavulanic acid, cephalotin, 3rd generation cephalosporins, etc.
The study of resistance to other antibiotics showed a moderately high rate for gentamycin, tobramycin, ciprofloxacin and cotrimoxazole, cefepime, aztreonam. Our strains, on the other hand, expressed a discrete level of resistance to imipenem and amikacin (Figure 4).

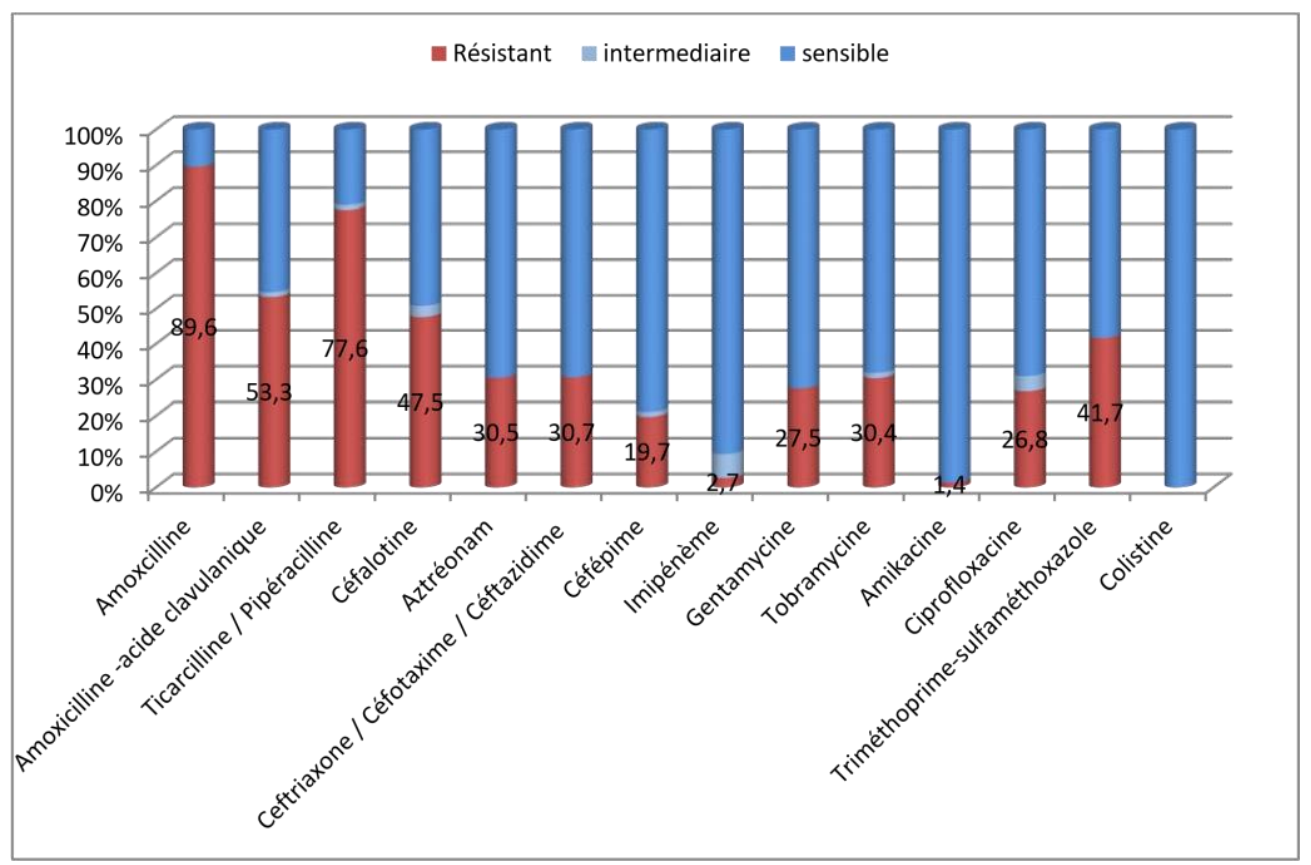

Figure 4: Resistance rates of enterobacteriaceae to different antibiotics (\%)

The study of the resistance of the main enterobacteria in our series shows that Proteus spp. has a lower rate of resistance to all antibiotics, compared to
Klebsiella pneumoniae and E.coli. The latter two bacteria have very similar resistance rates (Figure 5). 


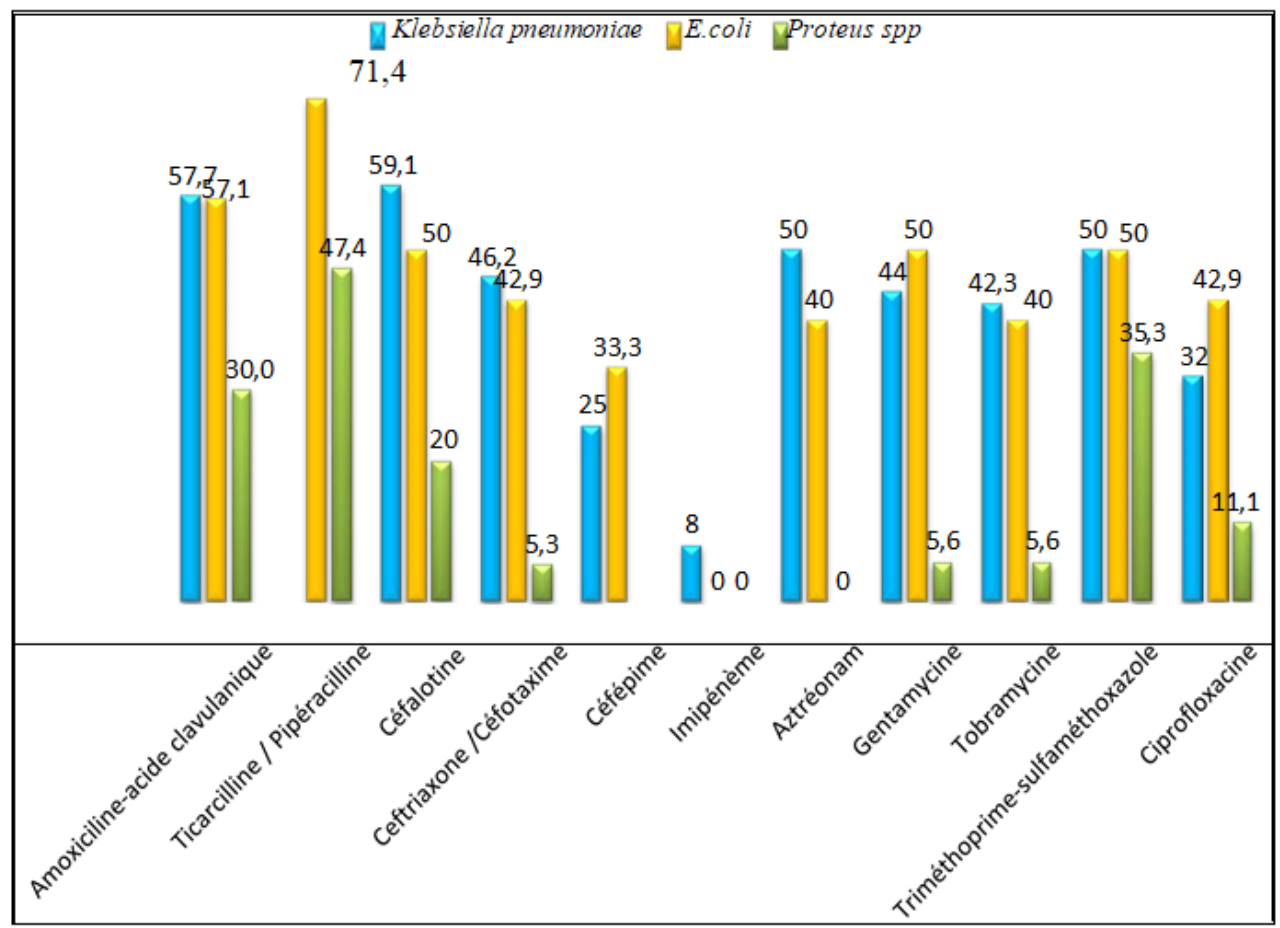

Figure 5: Resistance rates of different enterobacteria to different antibiotics

\section{Staphylococcus Aureus}

The resistance rate of Staphylococcus aureus was high for penicillin $\mathrm{G}$, amoxicillin, ticarcillin and piperacillin. The combination of amoxicillin and clavulanic acid, methicillin, cefotaxime, imipenem, aminoglycosides, lincomycin and possibly erythromycin and tetracycline showed good activity on strains isolated from Staphylococcus aureus.
All Staphylococcus aureus isolates were fully susceptible to amikacin, fusidic acid, rifampicin, cotrimoxazole, vancomycin and teicoplanin (Figure 6).

For the streptococcus and enterococcus strains, no acquired resistance was noted.

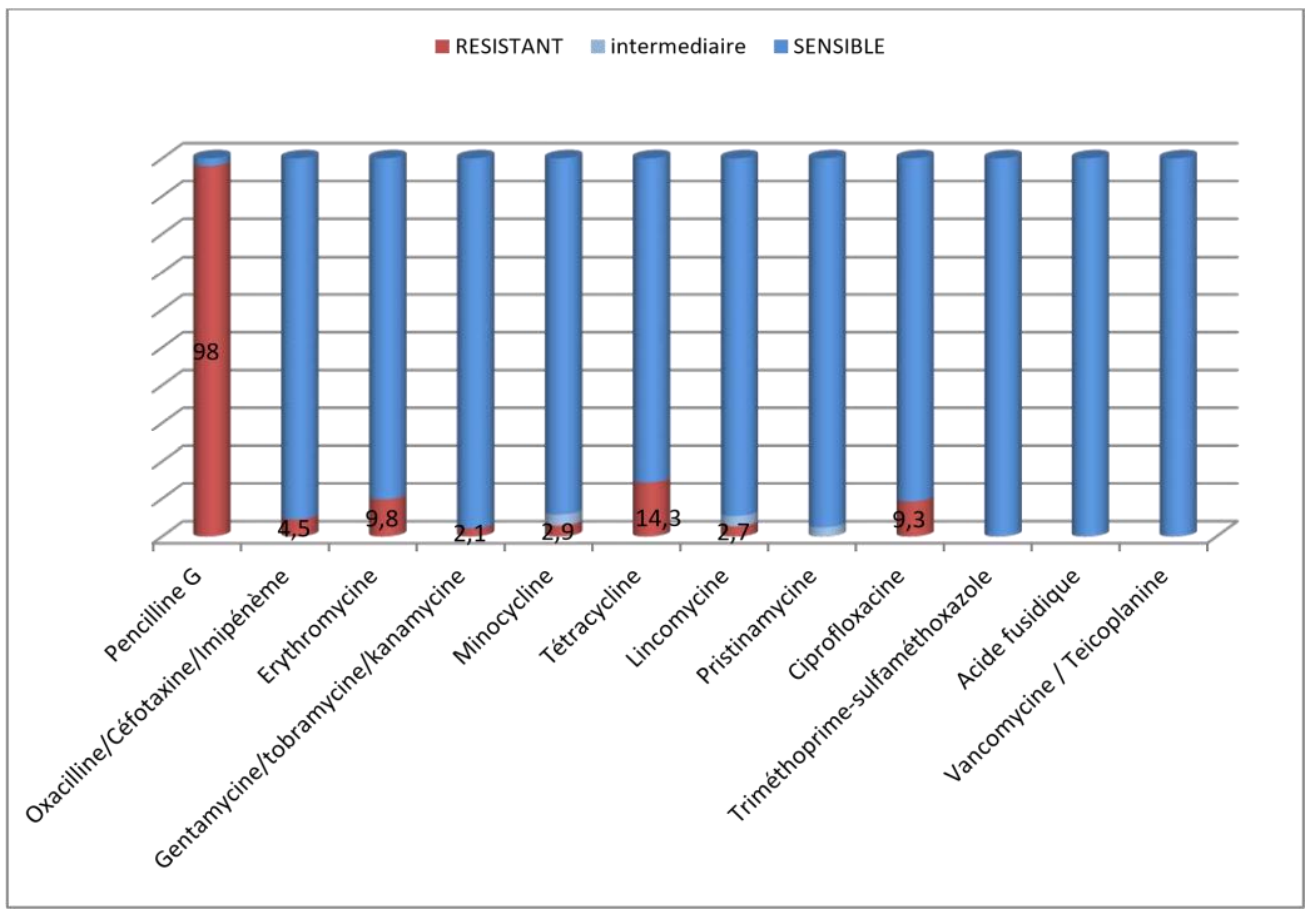

Figure 6: Rate of resistance of Staphylococcus aureus to different antibiotics (\%) 
I. Karrati et al; Sch J App Med Sci, Jan, 2022; 10(1): 63-71

In our series, we noted a clear predominance of young people and the average age was 35 years, which is in line with French studies (39 years) and Moroccan studies carried out at the university hospitals of Rabat and Casa [2, 3]. A higher average age of up to 64 years was noted in Egypt, Saudi Arabia, India and the United States [4-7].

For sex, there is a notable variability in the sex ratio between studies. However, male predominance is frequently noted. The reason for hospitalisation in our study was dominated by traumatic pathology (72.2\%), as in other Moroccan and European studies. Respiratory pathology is also a frequent reason for hospitalisation in several studies $[8,9]$.

The young age, the predominance of the male sex, the importance of traumatic pathology as the first reason for hospitalization and the low rate of comorbidities could be explained by the plague of public road accidents in the region of Marrakech, which essentially affects young males.

In the literature, the duration of hospitalization varies between 18 and 26 days. Our results are in line with those of the literature with an average duration of 19 days $[2,4,10]$ and an average delay of 6 days for the appearance of NP with a slight predominance of the late one. These results are also consistent with those reported in several similar studies $[2,3,11,12]$.

NP associated with another nosocomial infection was found in $15 \%$ of cases with a predominance of urinary tract infection; this association could be explained by the fact that $100 \%$ of our patients were intubated and sedated with a bladder catheterisation, as in other studies in Morocco, Egypt, Saudi Arabia and France [2, 3, 5, 13, 14]. Regarding other invasive procedures, the use of a central line was observed in $74 \%$ of cases. Tracheostomy, chest drainage and reintubation represent minimal percentages compared to other publications $[15,16]$.

On the clinical-paraclinical level, a retrospective study carried out in the ICU of the Avicenne Military Hospital in Marrakech over a period of 3 years showed the same data as in our population [17] with a mortality rate of $63 \%$, similar to the results found in publications from the Ivory Coast, China and India, however, this rate is still high compared to studies carried out in France, Italy and the United States; this variation could be linked to the degree of severity of the reason for hospitalisation [18-19-20].

\section{Microbiological Data}

In our study, 3 sampling methods were applied: PDS, BAL and TEA. The majority of the samples were PDS (57\%); other similar studies use the same types of samples, while others also use pleural samples and blood samples for bacteremia or serum antigens, especially streptococcal [8, 13, 16, 14, 21-23].

A negative culture after 48 hours of incubation was found in $11.7 \%$ of cases in our study. This is in line with the literature, such as two American and international studies. This rate remains low compared to studies conducted in the Czech Republic, Serbia and China.

In our study, cultures were polymicrobial in $69 \%$ of cases and monomicrobial in $31 \%$ of cases. Similar results to the results of our study have been reported by Quartin et al. and Mira et al. In contrast, studies from Morocco, Iran, Spain, Brazil and Thailand have shown the predominance of monomicrobial cultures [20, 24-26].

Our study showed the predominance of gramnegative bacillii with an isolation rate of $72 \%$. The isolation rate of gram-positive cocci was $28 \%$. The most frequent bacterial family was non-fermentative BGN followed by Enterobacteriaceae which represented $38.2 \%$ and $32.5 \%$ respectively. The most frequently isolated species were Acinetobacter baumannii followed by Staphylococcus Aureus which accounted for $30 \%$ and $21 \%$ respectively. These results are consistent with most studies in the literature reporting that NPs are dominated by BGNs of which non-fermentative BGNs are the most frequently isolated. The prevalence of bacteria in different studies show that Acinetobacter baumannii is the leading causative germ of NPs at slightly different rates. Staphylococcus Aureus ranks 2nd in most studies. Pseudomonas aeruginosa and klebsiella pneumoniae share the $3 r d$ position according to the studies $[12,27$, 28].

\section{Antibiotic resistance profile of Acinetobacter baumannii}

The results in terms of antibiotic resistance found in our study are alarming. Resistance of Acinetobacter baumannii to ceftazidime reached a very high level with pipercillin-tazobactam (98.5\%), ceftazidime $(98.6 \%)$, cefepime $(95.7 \%)$, gentamycin $(94.3 \%)$, amikacin $(84.3 \%)$, ciprofloxacin $(97.1 \%)$ and cotrimoxazole $(88 \%)$. The Acinetobacter baumannii strains isolated in our study expressed a high rate of resistance to imipenem $(95.7 \%)$ similar to those reported in studies [29-31].

\section{Antibiotic resistance profile of Pseudomonas aeruginosa:}

Our study showed the lowest rates of resistance of Pseudomonas aeruginosa to ceftazidime and imipenem compared to national studies or those conducted in Europe, Asia or the USA. Most other antibiotics remain active on our strains compared to other literature [32-34]. 
I. Karrati et al; Sch J App Med Sci, Jan, 2022; 10(1): 63-71

3. Enterobacteriaceae antibiotic resistance profile:

For all species of Enterobacteriaceae, the resistance rates to beta-lactams were in the same ranges described by the studies. However, for aminoglycosides, ciprofloxacin, cotrimoxazole and colistin, our strains were more susceptible than in other studies. For Klebsiella pneumonia, our strains were more sensitive to most antibiotics, especially in comparison with international studies. For E.coli, our strains were less resistant to cephalosporins compared to international studies. They did not show resistance to impenem and colistin. For Proteus spp, our strains were more resistant to penicillins and less resistant to the remaining beta-lactams and aminoglycosides compared to the studies consulted [12, 35-37].

\section{Antibiotic resistance profile of Staphylococcus aureus}

In our series, we found low resistance to methicillin, gentamycin, lincozamide, cotrimoxazole, minocycline and erythromycin compared to other studies. $98.2 \%$ of our strains were resistant to penicillin G. Vancomycin remained active against all strains of Staphylococcus aureus. This has been described in the literature $[38,32,36]$.

\section{Conclusion}

The control of nosocomial pneumonia remains a major concern in intensive care units throughout the world; but mainly, in developing countries.

Our study allowed us to describe the epidemiological and resistance profile of the germs responsible for nosocomial pneumonia during the year 2019 , based on the data available in the microbiology laboratory and the intensive care unit of Ibn Tofail Hospital. Therefore, this work constitutes a starting point for a better understanding of nosocomial pneumopathies; it should be supported by a multicentre study including several Moroccan and even Maghrebian intensive care units. Finally, the increased rate of bacterial resistance, and in this case to carbapenems, should reconsider our daily practices in terms of prevention and prescription of antibiotics.

\section{REFERENCES}

1. Spalding, M. C., Cripps, M. W., \& Minshall, C. T. (2017). Ventilator-associated pneumonia: new definitions. Critical care clinics, 33(2), 277-292.

2. Zegmout, A., Balkhi, H., Souhi, H., El Ouazzani, H., Rhorfi, A., \& Abid, A. (2017). Pneumopathies nosocomiales en réanimation: caractéristiques cliniques, biologiques et bactériologiques. Revиe des Maladies Respiratoires, 34, A96.

3. Ezzouine, H., Harbouze, N., \& Benslama, A. (2014). E-14: Pneumopathies nosocomiales chez les patients séjournant au long cours en réanimation: caractéristiques cliniques et bactériologiques. Médecine et Maladies

Infectieuses, 44(6), 39.

4. Othman, A. A., \& Abdelazim, M. S. (2017). Ventilator-associated pneumonia in adult intensive care unit prevalence and complications. The Egyptian Journal of Critical Care Medicine, 5(2), 61-63.

5. Al-Dorzi, H. M., El-Saed, A., Rishu, A. H., Balkhy, H. H., Memish, Z. A., \& Arabi, Y. M. (2012). The results of a 6-year epidemiologic surveillance for ventilator-associated pneumonia at a tertiary care intensive care unit in Saudi Arabia. American journal of infection control, 40(9), 794-799.

6. Bouadma, L., Sonneville, R., Garrouste-Orgeas, M., Darmon, M., Souweine, B., Voiriot, G., ... \& OUTCOMEREA Study Group. (2015). Ventilatorassociated events: prevalence, outcome, and relationship with ventilator-associated pneumonia. Critical care medicine,43(9), 17981806.

7. Lee, M. S., Walker, V., Chen, L. F., Sexton, D. J., \& Anderson, D. J. (2013). The epidemiology of ventilator-associated pneumonia in a network of community hospitals: a prospective multicenter study. Infection Control \& Hospital Epidemiology, 34(7), 657-662.

8. Koulenti, D., Tsigou, E., \& Rello, J. (2017). Nosocomial pneumonia in 27 ICUs in Europe: perspectives from the EU-VAP/CAP study. European journal of clinical microbiology \& infectious diseases, 36(11), 1999-2006.

9. Whiting, J., Edriss, H., \& Nugent, K. (2015). Frequency and etiology of ventilator-associated events in the medical intensive care unit. The American journal of the medical sciences, 350(6), 453-457.

10. Shimi, A., Touzani, S., Elbakouri, N., Bechri, B., Derkaoui, A., \& Khatouf, M. (2015). Les pneumopathies nosocomiales en réanimation de CHU Hassan II de Fès. Pan African Medical Journal, 22(1).

11. Nguessan, Y., Abhé, C, Tétchi, Y., Ouattara, A., Coulibaly, K., \& Brouh, Y. Facteurs pronostics des pneumopathies acquises sous ventilation mécanique dans un service de réanimation d'Abidjan.

12. Delle Rose, D., Pezzotti, P., Fortunato, E., Sordillo, P., Gini, S., Boros, S., ... \& Sarmati, L. (2016). Clinical predictors and microbiology of ventilatorassociated pneumonia in the intensive care unit: a retrospective analysis in six Italian hospitals. European Journal of Clinical Microbiology \& Infectious Diseases, 35(9), 15311539.

13. Xie, D. S., Xiong, W., Lai, R. P., Liu, L., Gan, X. M., Wang, X. H., ... \& Nie, S. F. (2011). Ventilator-associated pneumonia in intensive care units in Hubei Province, China: a multicentre 
I. Karrati et al; Sch J App Med Sci, Jan, 2022; 10(1): 63-71

prospective cohort survey. Journal of Hospital Infection, 78(4), 284-288.

14. Giard, M., Lepape, A., Allaouchiche, B., Guerin, C., Lehot, J. J., Robert, M. O., ... \& Vanhems, P. (2008). Early-and late-onset ventilator-associated pneumonia acquired in the intensive care unit: comparison of risk factors. Journal of critical care, 23(1), 27-33.

15. Erbay, R. H., Yalcin, A. N., Zencir, M., Serin, S., \& Atalay, H. (2004). Costs and risk factors for ventilator-associated pneumonia in a Turkish university hospital's intensive care unit: a casecontrol study. BMC pulmonary medicine, 4(1), 1-7.

16. Jaimes, F., De La Rosa, G., Gómez, E., Múnera, P., Ramírez, J., \& Castrillón, S. (2007). Incidence and risk factors for ventilator-associated pneumonia in a developing country: where is the difference?. Respiratory medicine, 101(4), 762767.

17. Chanfir, A. (2016). Les pneumopathies nosocomiales en milieu de réanimation à l'hôpiatl militaire Avicienne marrakech. Thèse de médecine Marrakech 2016; Nº6.

18. Behnia, M., Logan, S. C., Fallen, L., \& Catalano, P. (2014). Nosocomial and ventilator-associated pneumonia in a community hospital intensive care unit: a retrospective review and analysis. $B M C$ research notes, 7(1), 1-9.

19. Zhang, Z., \& Duan, J. (2015). Nosocomial pneumonia in non-invasive ventilation patients: incidence, characteristics, and outcomes. Journal of Hospital Infection, 91(2), 153-157.

20. Gvozdenović, L., Kolarović, J., Šarkanović-Lukić, M., Popović, M., \& Trivić, S. (2012). Incidence and outcome of ventilator-associated pneumonia (our experience). Brazilian Journal of Infectious Diseases, 16(6), 599-600.

21. García-Leoni, M. E., Moreno, S., García-Garrote, F., \& Cercenado, E. (2010). Ventilator-associated pneumonia in long-term ventilator-assisted individuals. Spinal Cord, 48(12), 876-880.

22. Werarak, P., Kiratisin, P., \& Thamlikitkul, V. (2010). Hospital-acquired pneumonia and ventilator-associated pneumonia in adults at Siriraj Hospital: etiology, clinical outcomes, and impact of antimicrobial resistance. J Med Assoc Thai, 93(Suppl 1), S126-38.

23. Esperatti, M., Ferrer, M., Theessen, A., Liapikou, A., Valencia, M., Saucedo, L. M., ... \& Torres, A. (2010). Nosocomial pneumonia in the intensive care unit acquired by mechanically ventilated versus nonventilated patients. American journal of respiratory and critical care medicine, 182(12), 1533-1539.

24. Japoni, A., Vazin, A., Davarpanah, M. A., Ardakani, M. A., Alborzi, A., Japoni, S., \& Rafaatpour, N. (2011). Ventilator-associated pneumonia in Iranian intensive care units. The Journal of Infection in Developing Countries, 5(04), 286-293.
25. Medell, M., Hart, M., Marrero, O., Espinosa, F., Oca, Z. M. D., \& Valdés, R. (2012). Clinical and microbiological characterization of pneumonia in mechanically ventilated patients. Brazilian Journal of Infectious Diseases, 16, 442-447.

26. El Idrissi, S. (2016). Les pneumopathies nosocomiales: prise en charge et pronostic (à propos de 50 cas). Thèse de médecine Marrakech 2016; $\mathrm{N}^{\circ} 40$.

27. Wałaszek, M., Kosiarska, A., Gniadek, A., Kołpa, M., Wolak, Z., Dobroś, W., \& Siadek, J. (2016). The risk factors for hospital-acquired pneumonia in the Intensive Care Unit. Przegl Epidemiol, 70(1), $15-20$.

28. Gupta, R., Malik, A., Rizvi, M., Ahmed, M., \& Singh, A. (2017). Epidemiology of multidrugresistant Gram-negative pathogens isolated from ventilator-associated pneumonia in ICU patients. Journal of global antimicrobial resistance, 9, 47-50.

29. Chaari, A., Mnif, B., Bahloul, M., Mahjoubi, F., Chtara, K., Turki, O., ... \& Bouaziz, M. (2013). Acinetobacter baumannii ventilator-associated pneumonia: epidemiology, clinical characteristics, and prognosis factors. International Journal of Infectious Diseases, 17(12), e1225-e1228.

30. Yang, Y. S., Lee, Y. T., Huang, T. W., Sun, J. R., Kuo, S. C., Yang, C. H., ... \& Chang, F. Y. (2013). Acinetobacter baumannii nosocomial pneumonia: is the outcome more favorable in non-ventilated than ventilated patients? BMC infectious diseases, 13(1), 1-8.

31. Marjane, Y. (2012). La Pneumopathie acquise sous ventilation mécanique et les risques infectieux associés aux dispositifs d'intubation respiratoire en réanimation à l'HMIMV de Rabat (Doctoral dissertation).

32. Balkhy, H. H., El-Saed, A., Maghraby, R., AlDorzi, H. M., Khan, R., Rishu, A. H., \& Arabi, Y. M. (2014). Drug-resistant ventilator associated pneumonia in a tertiary care hospital in Saudi Arabia. Annals of thoracic medicine, 9(2), 104-111.

33. Planquette, B., Timsit, J. F., Misset, B. Y., Schwebel, C., Azoulay, E., Adrie, C., ... \& Bédos, J. P. (2013). Pseudomonas aeruginosa ventilatorassociated pneumonia. predictive factors of treatment failure. American journal of respiratory and critical care medicine, 188(1), 69-76.

34. Yayan, J., Ghebremedhin, B., \& Rasche, K. (2015). Antibiotic resistance of Pseudomonas aeruginosa in pneumonia at a single university hospital center in Germany over a 10-year period. Plos one, 10(10), e0139836.

35. Resende, M. M., Monteiro, S. G., Callegari, B., Figueiredo, P. M., Monteiro, C. R., \& MonteiroNeto, V. (2013). Epidemiology and outcomes of ventilator-associated pneumonia in northern Brazil: an analytical descriptive prospective cohort study. BMC infectious diseases, 13(1), 1-6. 
36. Azzab, M. M., El Sokkary, R. H., Tawfeek, M. M., \& Gebriel, M. G. (2016). Multidrug-resistant bacteria among patients with ventilator-associated pneumonia in an emergency intensive care unit, Egypt. EMHJ-Eastern Mediterranean Health Journal, 22(12), 894-903.

37. Medell, M., Hart, M., Duquesne, A., Espinosa, F., \& Valdés, R. (2013). Nosocomial ventilator- associated pneumonia in Cuban intensive care units: bacterial species and antibiotic resistance. MEDICC review, 15, 26-29.

38. Lalaoui, S. (2016). Profil bactériologique des pneumopathies nosocomiales de l'adulte et état de résistance aux antibiotiques. Thèse de médecine Marrakech 2016; $\mathrm{N}^{\circ} 122$. 